\title{
Modeling the coastal ecosystem complex: present situation and challenges
}

\author{
Sachihiko Itoh ${ }^{1}\left(\mathbb{D} \cdot\right.$ Aigo Takeshige $^{2} \cdot$ Akihide Kasai $^{3} \cdot$ Shingo Kimura ${ }^{1}$
}

Received: 2 November 2017 / Accepted: 18 January 2018 / Published online: 13 February 2018

(c) The Author(s) 2018. This article is an open access publication

\begin{abstract}
To enhance numerical modeling of the coastal ecosystem complex (CEC), we reviewed the CEC and related concepts along with the current coastal ecosystem model framework in this study. We identified two model implementation paths from the initial objectives to numerical models: specific model building, and the use of existing model frameworks. As the CEC is still at the conceptual stage, both paths are possible. Four important ecological features of CEC modeling (population connectivity, habitat heterogeneity, ontogeny of organisms, and trophic interactions) were also identified. Models for population connectivity, species distributions, life histories, and food webs were categorized using these features. We found that some previously established concepts (between-habitat interactions, coastal ecosystem mosaic, and seascape nursery) overlap with the CEC concept. Several existing integrated model frameworks were reviewed, focusing on their potential to simulate CEC processes. Building specific models for the CEC at the current conceptual stage will be challenging, and modification of existing models will be needed if they are to be used for CEC modeling. Habitat function, ontogenetic development in early life stages, and recruitment variability are important factors when modifying existing models for the development of CEC models. Although model complexity should become high to reproduce observed ecoclogical processes, an intermediate level of model ccomplexity is feasible to decrease parameter uncertainty in models for fisheries management.
\end{abstract}

Keywords Model development $\cdot$ Population connectivity $\cdot$ Habitat heterogeneity $\cdot$ Ontogeny $\cdot$ Trophic interactions

\section{Introduction}

Ecosystem models are simplifications of natural realms (Odum and Barrett 2004). The modeling of ecosystems begins with the development of specific objectives.

This article is sponsored by the Coastal Ecosystem Complex Project of the Ocean Resource Use Promotion Technology Development Program, of the Ministry of Education, Culture, Sports, Science and Technology, Japan.

Sachihiko Itoh

itohsach@aori.u-tokyo.ac.jp

1 Atmosphere and Ocean Research Institute, The University of Tokyo, 5-1-5 Kashiwanoha, Kashiwa, Chiba 277-8564, Japan

2 National Research Institute of Far Seas Fisheries, Japan Fisheries Research and Education Agency, Yokohama, Japan

3 Faculty of Fisheries Sciences, Hokkaido University, Hakodate, Japan
Observations and analyses are needed to build a conceptual model, which is then developed as a numerical model by mathematical formulation of the relevant processes (Kremer and Nixon 1978). Simple mathematical models are often treated analytically, while complex models, such as those consisting of sets of time-dependent differential equations governing the evolution of state variables, must be integrated using computers (Fig. 1). As numerical ecosystem models are increasingly used for a variety of purposes, a high level of complexity is needed to represent more detailed processes, which requires substantial resources for formulation and coding. This argues for the cautious use of existing generic ecosystem model frameworks to simulate new concepts (Fig. 1), rather than constructing specific models for specific purposes. The use of an existing model framework may require fewer resources, but careful examination is needed, especially with regard to model attributes, scales and reproducibility for key functional groups (Essington and Plaganyi 2013). 
(a)

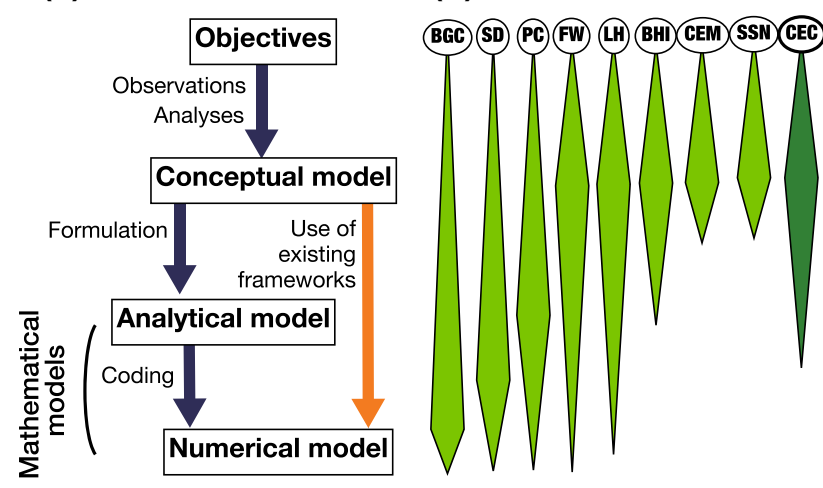

Fig. 1 Diagram of a model development pathways, and $\mathbf{b}$ the development stages of various models [biogeochemical cycles $(B G C)$, species distribution $(S D)$, population connectivity $(P C)$, food web $(F W)$, life history $(L H)$, between-habitat interactions $(B H I)$, coastal ecosystem mosaic $(C E M)$, seascape nursery $(S S N)$, and coastal ecosystem complex $(C E C)$ models]. Polygons extending from the ellipses indicate the typical development stage (the representative stage is at the maximum polygon width)

Marine ecosystems contain numerous organisms and materials that interact through physical, chemical, and biological processes. Numerical models of marine ecosystems at lower trophic levels usually consist of equations governing hydrodynamics, the chemical reactions of dissolved and particulate materials, and the behavior, interactions, and physiology of organisms; these are implemented in representative models (Fasham et al. 1990; Kishi et al. 2007; Moore et al. 2004; Shigemitsu et al. 2012). Although these models are mechanistically oriented, some equations and parameters, especially those for biological processes, are empirically determined because the principles governing ecological systems are less well established than those for physical systems (Okubo and Levin 2001).

Although marine areas are ultimately interconnected, local geographical and hydrographical factors typically characterize local ecosystems. Coastal areas are partially isolated by the shoreline and are often strongly influenced by local topography, tides, currents, meteorological forcing, terrestrial systems, and anthropogenic impacts; these factors form unique ecosystems in each area. An important aspect of coastal ecosystems that distinguishes them from open ocean ecosystems is the presence of benthic habitats. Vegetated coastal habitats, including seagrass beds, seaweed meadows, mangroves, and salt marshes, are highly productive (Duarte 2017; Mann 2000). Benthic microalgae are also important primary producers, and in some areas their contributions to total primary production are comparable to those of phytoplankton in the water column (Underwood and Kromkamp 1999). These vegetated habitats, and other biotic habitats including coral reefs, support a variety of animals (Nishihira 2006; Onaka et al. 2013).
The coastal ecosystem complex (CEC) is defined as an ecosystem network linking organisms and habitats in coastal areas (Watanabe et al. 2018). Commonly recognized habitats that form part of the CEC include mud flats at river mouths, seagrass beds, seaweed communities, rocky intertidal shores, sandy beaches, coral reefs, and mangroves. The CEC is hypothesized to play critical roles in sustaining the marine animals that occupy various habitats in coastal areas. In temperate waters, including those around Japan, coastal habitats are not static and are often subject to considerable seasonal and intra-seasonal fluctuations, which increases the complexity of the CEC. Many fish species, both coastal and migratory, utilize various habitats during different seasons and/or during different life stages.

As the CEC concept is evolving but still at the conceptual stage, studies investigating CEC processes through numerical modeling are limited. Some existing model frameworks appear to be capable of modeling the CEC, but the components and processes required to develop CEC models have not been thoroughly specified. Nevertheless, there are numerous numerical models of coastal ecosystems (Allen et al. 2012; Baretta-Bekker et al. 1997; Butenschön et al. 2016; Fulton et al. 2004a; Hata et al. 2004; Kishi et al. 1981; Sohma et al. 2004), formulated for particular purposes. Models including higher trophic levels (Coll et al. 2016; Fennel 2008; Fulton 2010; Halouani et al. 2016; Kishi et al. 2011; Rose et al. 2015) have reproduced complex food webs and/or the migratory behavior of fish.

This report is organized into several sections, as follows. In the section "Modeling the CEC" we review components and concepts that are needed to model the CEC. In the section "Existing frameworks of integrated numerical models" we review representative integrated numerical models, including some case studies. In the section "Model applications and challenges" we discuss possible future challenges in developing a model for the CEC. In the final section we provide an overall summary.

\section{Modeling the CEC}

\section{Basic components}

As the CEC affects organisms that use multiple habitats in coastal ecosystems, the main target organisms of CEC models are those with multiple life stages and annual or longer life spans. In this context the present review focuses on model processes and components related to the production of fisheries associated with the CEC, although animals of conservation concern can be considered in similar CEC models.

Although fish productivity involves the transfer of energy from primary production, and losses resulting from 
metabolism and mortality (Fennel and Neumann 2004), model representations of these trophic interactions and species ecology have often been simplified. Some models have considered a limited number of commercial fish species based on lower trophic levels including nutrient dynamics and zooplankton (Ito et al. 2004; Megrey et al. 2007), while others have considered the food web structure commencing at primary producers and omitting nutrient dynamics (Coll et al. 2006; Gaichas et al. 2009). Most fish population models, including those based on virtual population analysis (Mangnússon 1995; Quinn and Deriso 1999), have been limited to fish species separated into age cohorts. End-to-end models include all trophic levels, including fishery activities (Fulton 2010; Rose et al. 2015), but typically not all species in the ecosystem are considered. In coastal waters of Japan, many fisheries involve low trophic levels including seaweed and filter-feeding bivalves. In these cases, low trophic level water-quality models can be used to evaluate the variability of target organisms (Kishi and Uchiyama 1995; Yoon et al. 2013).

Classically, low trophic level ecosystem models use nutrients or biomass as the currency in the model to evaluate exchange among organisms and materials (Kremer and Nixon 1978). However, higher trophic level species that are the focus of CEC models increase considerably in weight and decrease in number as they progress from the egg to adult stages; consequently, two variables (biomass and number, or weight and number) need to be considered (Fennel 2008). These have been considered separately in some studies (Kimura et al. 1992; Kishi et al. 1991), or integrated within a single model (Fennel 2008; Fulton et al. 2007; Radtke et al. 2013; Rose et al. 2015). Age-structured population models (Hilborn and Walters 1992; Quinn and Deriso 1999) partly represent these two components through the relationship between age and size.

\section{Connectivity, heterogeneity, ontogeny, and trophic interactions}

A key feature for inclusion in CEC models is spatial connectivity among habitats, which should reflect the ontogeny of the target species. In numerical modeling this involves both spatial and temporal dimensions. In addition, as prey and predators of the target species also undergo ontogenetic changes, the model needs to consider low to high trophic levels. These components are not always fully incorporated into numerical ecosystem models. Nevertheless, conceptual models have been developed, and simplified numerical models are often used to investigate selected processes such as biophysical dispersion (the advection, diffusion, and migratory behavior of organisms). In this subsection we review conceptual models and simplified numerical models for the above components, which are shown schematically in Figs. 1 and 2. Frameworks for integrated numerical models partly implementing the above processes, and case studies, are discussed in the next subsection.

Four ecological factors are derived from the key features of the CEC noted above: organism/material connectivity, habitat heterogeneity, ontogeny, and trophic interactions (Fig. 2). These features can be used to categorize conceptual models from a more technical perspective, such as representation of model domain prey/predator interactions; however, not all concepts (including CEC) have been developed to the numerical model stage. In the following sub-subsections we review simple models by considering each of the four features, and then discuss how more complex models are categorized using these features.

\section{Population connectivity models}

Connectivity in marine ecosystems has been most intensively considered in the context of metapopulations (Kritzer and Sale 2006). Small eggs and larvae of marine fishes and invertebrates are strongly influenced by currents, and large numbers can be dispersed both close to spawning sites and to distant areas (Jones et al. 2009; Lipcius et al. 2008). For coastal and benthic species, settlement occurs after a planktonic larval stage, followed by reproduction to contribute to population connectivity (Cowen and Sponaugle 2009).

A number of studies have conducted numerical simulations to quantitatively evaluate population connectivity. Core aspects of the population connectivity models (covering the population connectivity circle in Fig. 2) are based on the physical processes of advection and diffusion; these models are often extended to include the mortality and behavior of target organisms (Cowen 2000; Mitarai et al. 2009; Miyake et al. 2011; Werner et al. 2007). These models use physical parameters (velocity, temperature, and salinity) from hydrodynamic models, and estimate the distributions of organisms through Eulerian (an advection-diffusion-reaction

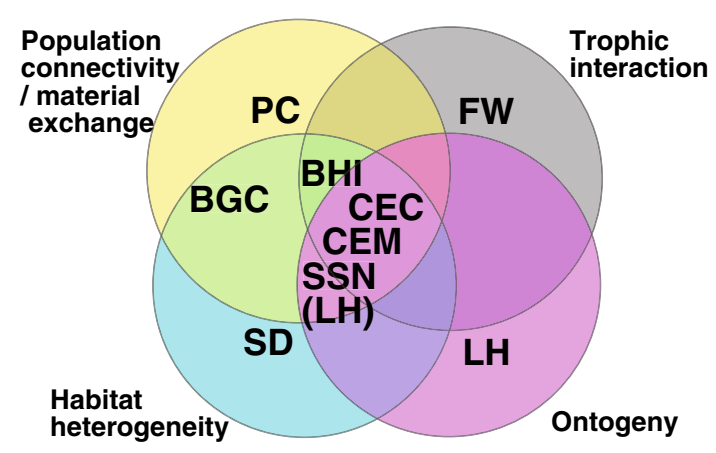

Fig. 2 Four important ecological features of the concept of the CEC. Each circle indicates a feature that can overlap with other features. Models are plotted in areas corresponding to features they conceptually include. For model abbreviations, see Fig. 1 
equation for concentration) or Lagrangian (particle tracking) approaches. In evaluating connectivity, so-called dispersal kernels or connectivity matrixes (Cowen and Sponaugle 2009; Mitarai et al. 2008) are commonly used. An important component that distinguishes connectivity models from simple physical transport is migration. Some connectivity models consider vertical migration of planktonic larvae (e.g., Paris et al. 2013), whereby the larvae settle in a suitable habitat or move horizontally using selective tidal stream transport (Cowen 2002; Criales et al. 2015; de Graaf et al. 2004; Savina et al. 2016). The CEC concept includes population connectivity on a timescale of a generation, but also the life span timescale (e.g., ontogenetic habitat shift). Despite this, numerical models primarily focused on population connectivity can also be used to investigate ontogenetic habitat connectivity.

\section{Species distribution models}

Species distribution (SD) models (or habitat models) predict the occurrence or abundance of organisms using environmental information (Elith and Leathwick 2009), and so are tightly linked to habitat heterogeneity (Fig. 2). These are generally statistical models that are constructed using observed habitat-organism relationships. Various statistical algorithms, including generalized linear models, generalized additive models, and maximum entropy models, are used to predict the distribution of marine organisms (Jones et al. 2012; Murase et al. 2009; Pittman and Brown 2011; Reiss et al. 2011). Although SD models are powerful tools for evaluating the spatial distribution of organisms in diverse habitats, they are usually empirical and most of them cannot provide mechanistic predictions.

The dynamic bioclimate envelope model (DBEM) developed by Cheung et al. (2008) predicts changes in the distribution of marine organisms driven by climate change. The DBEM first estimates the species distribution based on the environmental preference (bioclimate envelope) of the current climate, and then predicts the future distribution considering not only the changes in the environmental variables but also various ecological processes such as growth, mortality, larval dispersal, and migration (Cheung et al. 2008, 2015). As the DBEM can make predictions using physical and biogeochemical data from developed numerical models, it may also be useful in coastal ecosystems when considering the response of organisms to natural/anthropogenic environmental changes.

\section{Life history models}

If target species have multiple life stages with different characteristics, understanding life history traits is an important step in building a CEC model (Fig. 2). As described in other contributions to this special issue, many fish and invertebrates in coastal areas are transported passively during planktonic larval stages, grow in nursery habitats, then recruit into adult habitats when they mature; this is accompanied by changes in feeding habitat (Kasai et al. 2018; Kurita et al. 2018; Ohtsuchi et al. 2018; Shirafuji et al. 2018; Takami and Kawamura 2018). Therefore, life history models for coastal animals, even those involving single species, are tightly linked to population connectivity, habitat heterogeneity, and trophic interactions (Fig. 2). Numerical individualbased models (IBMs) that consider individual attributes, and keep records of past biogenic states, are commonly used in the development of life history models (e.g., Savina et al. 2016). To be developed into an ecosystem model, other organisms and materials that are trophically linked to the target species need to be included.

\section{Food web models}

Trophic interactions are typically presented graphically as a food web diagram, which is also a conceptual model (Fig. 2). A food web diagram enables the "players" (organisms/materials) and their possible interactions to be represented. Ecopath with Ecosim (EwE) is a representative and widely used numerical food web model that estimates the abundance and relative strength of prey-predator interactions through an assumption of mass balance (Christensen and Walters 2004; Kiyota et al. 2016; Yonezaki et al. 2016). Ecopath is a static mass balance food web model that can be included in the trophic interaction circle (Fig. 2). Ecosim can incorporate temporal changes in the mass balance, and Ecospace includes spatial dimensions (Christensen et al. 2014; Pauly et al. 2000; Walters et al. 1999). A review of Ecospace, which can numerically express the four features in Fig. 2, is provided in the next section ("Existing frameworks of integrated numerical models").

\section{Concepts coupling the four features}

Although marine population connectivity models focus primarily on the movement of target organisms, resources for their production and their predators also move among habitats. Inputs of inorganic nutrients and organic materials into a marine habitat (termed allochthonous inputs) are key components of between-habitat interactions (BHIs) (Hori 2008). As Hori (2008) also considered the role of predators in exchanging inputs over different trophic levels, BHI includes connectivity and habitat heterogeneity, but also trophic interactions (Fig. 2).

While BHIs mainly focus on the community structure in a coastal ecosystem (Hori 2008), allochthonous input is broadly related to biogeochemical cycles (Fig. 2). For example, riverine fluxes of inorganic nutrients and organic 
matter into coastal waters are major components of carbon and nutrient cycles (e.g., Cai 2011). Many three-dimensional models coupling hydrodynamics and low trophic level ecosystem models have been developed and used to investigate coastal biogeochemical cycles. Amongst these are the European Regional Seas Ecosystem Model (ERSEM) (Allen et al. 2012; Baretta et al. 1995; BarettaBekker et al. 1997; Butenschön et al. 2016) and those reviewed by James (2002) and Moll and Radach (2003). Biogeochemical models for Japanese coastal waters have also been developed (Hata et al. 2004; Sohma et al. 2001, 2004, 2008). Of note, the BHI concept proposed by Hori (2008) focused more on the spatial heterogeneity of habitats within a coastal area, which is different from numerical studies of biogeochemical/material cycles at larger scales, often considering areas with a homogeneous benthic habitat (Cranford et al. 2007; Lacroix et al. 2007; Nobre et al. 2010; Xu and Hood 2006).

As suggested in the above discussion, spatial scales and coastal habitat heterogeneity are important parameters related to connectivity. The metapopulation concept has been extended to metacommunities (Wilson 1992) and further to meta-ecosystems (Loreau et al. 2003), which couples local ecosystems at seascape (equivalent to terrestrial landscape) or regional scales through flows of energy, materials, and organisms (Loreau et al. 2003). Menge et al. (2015) proposed a conceptual hierarchical meta-ecosystem model that considers local community responses to oceanographic connectivity over multiple spatial scales. Although numerical ecosystem models coupled with high-resolution hydrodynamic models could reproduce multi-scale interactions between meta-ecosystems, these concepts have yet to be fully developed into numerical models.

Coastal seascape is defined as "a spatially heterogeneous area of coastal environment" (Bostrom et al. 2011). Although the seascape and CEC concepts differ, individual components, including seagrass beds, seaweed meadows, tidal flats, and rocky shores, are common to both concepts. One exception is that the CEC often considers microhabitats (Takami and Kawamura 2018) that are generally defined to be distributed within a typical habitat, as mentioned above (Cuadros et al. 2017).

The importance of the heterogeneity of habitats and their connectivity within a seascape were highlighted by Sheaves (2009), and termed the "coastal ecosystem mosaic" (CEM). According to this concept, processes including the movement and dispersal of flora and fauna, nutrient exchange, consumption-recycling, and prey-predator interactions are considered to be important for various coastal organisms; e.g., those inhabiting estuarine, mangrove, and subtidal ecosystems. The CEM is thus plotted onto the central area in Fig. 2 with the CEC, where the four features overlap.
Nagelkerken et al. (2015) reviewed the functions of habitat patch mosaics in seascapes as nurseries for coastal animals, and referred to these as "seascape nurseries" (SSNs). They considered core nursery habitats within the mosaic where abundance or productivity occurs, and the migration pathways connecting nurseries to adult populations (termed "ecosystem corridors"), which are critical for sustaining life cycles. Compared with the CEM, the SSN concept defined by Nagelkerken et al. (2015) is focused more on the life history of the fish species and less on their trophic interactions (Fig. 2).

The CEM (Sheaves 2009) and SSN (Nagelkerken et al. 2015) concepts are relatively recent and have not yet been developed into numerical models. However, the ideas involved have been validated through field surveys and metaanalysis of seascapes including mangrove/seagrass/coral reef habitats and littoral/intertidal/subtidal habitats (Adkins et al. 2016; Barbour et al. 2014; Davis et al. 2014; Olds et al. 2012; Skilleter et al. 2017).

\section{Existing frameworks for integrated numerical models}

\section{Biogeochemical model coupled with individual-based model}

While low trophic level ecosystem (biogeochemical) models with components up to the level of plankton have been developed and become more sophisticated (Aumont and Bopp 2006; Butenschön et al. 2016; Doney et al. 2009; Kishi et al. 2007; Le Quere et al. 2005; Shigemitsu et al. 2012), the inclusion of higher trophic levels remains challenging. One approach is to couple a biogeochemical model to an individual-based model (IBM) for higher trophic level species. The object-oriented Simulator of Marine Ecosystem Exploitation (OSMOSE) (Shin and Cury 2001, 2004), North Pacific Ecosystem Model for Understanding Regional Oceanography for Including Saury and Herring (NEMURO. FISH) (Megrey et al. 2007), and NEMURO for Including Sardine and Anchovy (NEMURO.SAN) (Rose et al. 2015) are models that take this approach. Although original versions of these models do not include benthic habitats, this approach coupling a biogeochemical model with an IBM is important, as these components are generally more accessible and easier to handle than Ecospace and Atlantis that are reviewed in the following subsection. It is also noted that some biogeochemical models coupled pelagic and benthic ecosystems (e.g., Sohma et al. 2008; Butenschön et al. 2016).

The core part of OSMOSE is an IBM for multiple species of fish (Shin and Cury 2001). Clusters of fish individuals (super-individuals) migrate horizontally in the model 
domain, feed on smaller fish, are eaten by larger fish within the same grid, grow, decrease in number through starvation and fishing mortality, and reproduce (Shin and Cury 2001). As complex prey-predator interactions are simplified in the size-based opportunistic predation process, many fish species can efficiently be included in the OSMOSE model. Using OSMOSE, Cury and Shin (2004) reproduced the fish size distribution found in empirical studies.

OSMOSE has often been coupled with lower trophic level systems based on satellite chlorophyll $a$ (Grüss et al. 2015) and biogeochemical models (Halouani et al. 2016; Travers-Trolet et al. 2014). Travers-Trolet et al. (2014) investigated the effects of the combined pressures of fishing and climate forcing in the southern Benguela ecosystem using a hydrodynamic lower trophic level OSMOSE-coupled model. This suggested important roles for intermediate trophic level foraging fish under the combined pressures. Halouani et al. (2016) also developed a coupled model using OSMOSE for the coastal ecosystem of the Gulf of Gabs, Tunisia (OSMOSE-GoG). This incorporated the results of a multi-scale species distribution model (Hattab et al. 2014) and provided realistic results.

Although habitat information was indirectly considered in the OSMOSE-GoG model (Halouani et al. 2016), it cannot be used directly as a CEC model because habitat-species associations came directly from the species distribution model. Furthermore, the benthic production system is an important component in CEC models, but is not necessarily considered in models focusing on trophic interactions within pelagic layers, including OSMOSE-GoG (Halouani et al. 2016) and NEMURO.SAN for sardine and anchovy in the California Current System (Fiechter et al. 2016; Rose et al. 2015). Nevertheless, it is possible to use model frameworks coupling a biogeochemical model and fish IBM to investigate the CEC processes, provided that the biogeochemical models explicitly consider benthic habitats and their various biogeochemical processes.

\section{Ecospace}

Ecospace is a spatial food web model developed from the EwE model (Walters et al. 1999). As briefly reviewed above, the EwE model assumes the conservation of total biomass in a food web and estimates the biomass of organisms comprising the food web, and their consumption (exchange of biomass between prey and predator) rates. Ecopath calculates a steady state and Ecosim considers temporal evolution (Christensen and Walters 2004). EwE models can often encompass the entire food web under consideration, and the number of functional groups of organisms that can be included is generally greater than in the coupled biogeochemical and IBM models described above. Ecospace introduces a spatial dimension to EwE models, enabling consideration of habitat heterogeneity, and also marine protected areas (Walters et al. 1999).

The foraging arena concept introduced in Ecosim (Christensen and Walters 2004) separates prey biomass into vulnerable (consumed by predators) and non-vulnerable (not consumed by predators) parts. This occurs in nature, such as in the case of fish hiding in vegetated habitats or coral reefs. Irrespective of the ecological situation, the partition rate (vulnerability rate) controls the functional response of predators feeding on prey, and the model results are generally highly sensitive to this parameter (Christensen and Walters 2004).

In the original version of Ecospace, each cell in a domain is occupied by one habitat type (Walters et al. 1999). This can occur if the spatial resolution is high enough to resolve the habitat mosaic, but is difficult to achieve in food web models involving numerous functional groups. To overcome this problem, Christensen et al. (2014) introduced a habitat capacity model, which calculates the habitat capacity of each cell by multiplying the preference functions of multiple environmental factors for each functional group, thereby enabling cumulative impacts of multiple environments to be considered in the model (Christensen et al. 2014).

Using the version of Ecospace including a habitat capacity model, Coll et al. (2016) developed a model for the Southern Catalan Sea (northwest Mediterranean) ecosystem. They used environmental and phytoplankton biomass from hydrodynamic and pelagic biogeochemical models to force Ecospace to consider the proportions of the various substrate types (including mud, sand, and rock), and included 40 functional groups and four fishing fleets. Distributions and abundances of commercially important fishes were reproduced in the model. The model results suggested that the historical impacts of fishing and environmental conditions were not additive, but were synergetic or antagonistic.

Ecospace coupled with hydrodynamic and lower trophic level models, similar to that used by Coll et al. (2016), offers the potential to investigate the effects of coastal habitats on the distribution, movement, and detailed trophic interactions of both pelagic and benthic organisms. If Ecospace is applied to analysis of the CEC, the outputs from a pelagic-benthic coupled biogeochemical model is preferable for the input data, as various types of benthic production are important for benthic fauna. With the EwE model and Ecospace it is possible to define functional groups including multiple cohorts (termed "stanza") such as the juvenile/adult stanza, and resident/migratory relationships (Christensen et al. 2005), which are important for CEC models.

\section{Atlantis}

The Atlantis framework was developed for use in management strategy evaluation (Fulton 2010), and thus includes 
various non-ecological modules including those for harvesting, assessment, and economics (Fulton et al. 2004a, 2007, 2011). In this review we have focused on biophysical submodels (including fishing fleets) within the Atlantis framework, and hereafter the term "Atlantis" is used to refer to this subset.

As an ecosystem model, Atlantis has incorporated various components of other models (Fulton et al. 2004a). The Atlantis prototype was Bay Model 2 (Fulton et al. 2004b), a trophically diverse biogeochemical model that included four fish groups and their predators; one of its precursors was ERSEM (Baretta et al. 1995). As an end-to-end model, Atlantis deterministically links physics to apex predators and fishing activities (Fulton et al. 2004a).

Unlike many biogeochemical models coupled with hydrodynamic models, Atlantis does not use the same grid coordinates as hydrodynamic models, but rather irregular polygons that correspond to geographical features and benthic habitat types (Fulton et al. 2004a, 2007). Hydrodynamic and other physical forcings are not coupled online with the main module, but are coupled offline as time series data. Physical factors are in some cases calculated using high-resolution hydrodynamic models (Fulton et al. 2004a, 2007) such as the Regional Ocean Modeling System (Haidvogel et al. 2008; Shchepetkin and McWilliams 2005). By using an arbitrary grid system, Atlantis can readily express the composition of habitat types in a polygon; fine-scale mixing processes sometimes need to be tuned using a mixing parameter. The habitat types include canyons, soft bottoms, flats, reefs, seagrasses, macroalgae, and mangroves, and three habitat types formed by filter feeders (Fulton et al. 2007). The area of biotic habitat fluctuates dynamically in response to the growth and mortality of habitat-forming organisms. Consideration of these various habitat types is important if Atlantis is to be applied to model CECs.

Using Atlantis, Girardin et al. (2016) investigated ecological processes related to the biomass fluctuations of two commercially important flatfish species (common sole and European plaice) in the eastern English channel (EEC). The model they developed (Atlantis-EEC) resolved physical and biotic habitat types and the main nursery grounds of the target species within the EEC, and included 40 functional groups. Vertebrates, including fish groups, were separated into ten age classes. Fisheries were explicitly considered through the inclusion of fishing fleets. While the trophic structure around the target species was derived from parameter calibration using data from various sources (the main purpose of the study), it was also shown that nutrient inputs from estuaries were important because they support productivity in the nursery grounds for sole and plaice.

Integrated models based on Atlantis have also been constructed for the Gulf of Mexico (Ainsworth et al. 2015), Chesapeake Bay (Ihde et al. 2016), Guam (Weijerman et al.
2015, 2016), and the California Current System (Kaplan et al. 2017). These models were primarily developed to be used for research questions and hypothesis testing, though applications for strategic management decisions have included planning fishery restructuring in Southeast Australia (Fulton et al. 2014), testing environmental impacts of groundfish harvest in the California Current (Pacific Fishery Management Council, and National Marine Fisheries Service 2015; Kaplan and Marshall 2016) and informing seafood eco-labeling standards (Marine Steward Council 2014; Smith et al. 2011). Recent applications relevant to CEC processes include Atlantis modeling of habitat and nutrient effects in the very shallow Chesapeake Bay on the US East Coast (Ihde and Townsend 2017), and modeling terrestrial inputs, warming, ocean acidification, and the benefits of coral habitat in Guam (Weijerman et al. 2015). Atlantis thus has the potential to simulate connectivity, habitat heterogeneity, the ontogeny of organisms, and trophic interactions (Fig. 2).

\section{Model applications and challenges}

\section{Possible applications: case studies in this special issue}

As noted in the section "Modeling the CEC", the CEC concept is still evolving, and numerical modeling has yet to be completed. Even in this special issue concerning the CEC, most of the papers focus generally on concepts. In this subsection we review several studies included in this special issue in terms of the conceptual diagrams shown in Figs. 1 and 2, and discuss the applicability of numerical models.

Kasai et al. (2018) and Fuji et al. (2018) focus on the migration of temperate seabass between estuaries and coastal areas. As reviewed by Kasai et al. (2018), eggs and larvae are transported shoreward from offshore spawning grounds, and juveniles settle in coastal areas. Some of the juveniles migrate upstream in rivers, using either tidal flows or salt wedges (Fuji et al. 2018), while others do not. Fuji et al. (2014) found that the growth of juveniles moving upriver from the Yura River Estuary (Japan) was initially poor, but rapidly increased during the time spent in the river, possibly because of the better availability of food. In the modeling context shown in Fig. 2, this seabass production system, involving offshore and coastal areas and estuaries, includes population connectivity, habitat heterogeneity, and ontogeny components. Takeshige et al. (unpublished data) used Atlantis to model the CEC in Tango Bay (Japan), and included seabass and several other fish species. While the planktonic larval period could not be included in Atlantis in their study, the contrasting growth histories of the two 
seabass groups (those ascending or not ascending the river) were successfully reproduced.

Ontogenetic habitat shift is one of main topics of this issue (Hayakawa et al. 2018; Kurita et al. 2018; Minami et al. 2018; Ohtsuchi et al. 2018; Shirafuji et al. 2018; Takami and Kawamura 2018). Clear shifts during early life history stages have been observed for Pacific herring (Shirafuji et al. 2018), Japanese flounder (Kurita et al. 2018), abalone (Takami and Kawamura 2018), turban snails (Hayakawa et al. 2018), kelp crabs (Ohtsuchi et al. 2018), and Japanese sea cucumber (Minami et al. 2018). The results of these studies can in part be interpreted as conceptual life history models (related to the ontogeny component in Fig. 2) that also consider habitat heterogeneity. The ontogenetic habitat shifts investigated in these studies were attributed mainly to spawning-substrate associations and diet shifts, although shelter effects might be important for structural habitats such as kelp beds (Hayakawa et al. 2018). The above conceptual life history models can be developed into numerical models that resolve various habitats and their functions, each of which is appropriate for the growth and survival of organisms at specific growth stages.

In contrast to the "serial" habitat shift with respect to the life stages noted above, multiple habitats are sometimes available "in parallel" at one life history stage, as is the case for the Manila clam (Hasegawa et al. 2018; Ichimi et al. unpublished data). Ichimi et al. (unpublished data) report that larval Manila clams in the eastern Seto Inland Sea (Japan) are widely dispersed and settle onto tidal flats (thought to be the main adult habitat), but also onto shingle beaches, where a high clam density was observed. The temperature conditions in summer were more moderate at the shingle beaches than on the tidal flats, suggesting they may be an oasis during severe heat waves. The settlement of Manila clam onto both tidal flats and shingle beaches occurs primarily because of the widespread dispersal of planktonic larvae, suggesting that other marine organisms that have planktonic larval stages may also use multiple habitats in parallel. In other cases, mobile organisms including fish can choose habitats that are suitable in particular situations, as is the case for juvenile seabass, which actively select either estuarine or coastal areas (Kasai et al. 2018). The parallel use of habitats is therefore related to population connectivity and habitat heterogeneity (Fig. 2). As reported by Hasegawa et al. (2018), numerical models of population connectivity, such as particle tracking models for biological behavior, are useful for this purpose.

A graphical representation of a CEC is shown schematically in Fig. 3, which conceptually models habitat connectivity for various species in a Japanese temperate coastal water such as Tango Bay (Hayakawa et al. 2018; Kasai et al. 2018; Takeshige et al., unpublished data). It is noted that this graphical model does not represent the details of the
Tango Bay ecosystem but highlights general processes and components of a CEC to be included in the model. Although some specific species (such as yellowtail, temperate seabass, Japanese flounder, Japanese anchovy and mysid Orientomysis japonica) are considered to play important roles in the Tango Bay ecosystem, they are included within generic functional groups aggregating similar species with respect to ecological functions. The diagram shows the CEC as a network consisting of various (heterogenetic) places that are connected to each other. The organisms visit various places for spawning, feeding, avoiding predation, or for other reasons that are determined ontogenetically and/or by phenology. In this model, the two piscivorous fishes are the main functional groups of focus; the ontogenetic habitat shifts and interactions with other functional groups (organisms/materials) are schematically shown in the figure. River discharge is one of the primary physical forcings affecting primary production in various coastal habitats mainly through distributing nutrients, and migrations of predators and forage fish are also included. This diagram conceptualizes the CEC network over various seasons and includes multiple organisms at various trophic levels together with temporal and spatial dimensions. Consequently, it makes a useful contribution to development of numerical modeling. It is also noted that dynamic simulations of this kind of conceptual model may use qualitative network models (Melbourne-Thomas et al. 2012), which is useful especially when there are insufficient data to validate the model (Harvey et al. 2016).

\section{Challenges}

Building a specific numerical model for CEC analysis from a concept (Fig. 1) is clearly a major challenge. As discussed in previous sections, models should incorporate four components-population connectivity, habitat heterogeneity, ontogeny of organisms, and trophic interactions-at least to some degree (Fig. 2). Technically, this requires that temporal and spatial dimensions, and a sufficient number of trophic levels and functional groups, be included. Based on the case studies in this special issue, resolving fine distinctions among physical and biotic habitat types and inclusion of the entire life cycle may be important. Numerical modeling of all of these factors requires substantial effort, and its development may best be advanced by modifying existing numerical models. Thus, the pathway for building specific models may not be completely separate from the pathway of the existing framework (Fig. 1).

Although some model frameworks reviewed in this paper, including Ecospace and Atlantis, may be capable of simulating important CEC processes (e.g., Takeshige et al., unpublished data), modification of these generic models for specific purposes is likely to improve their results. Below, we consider three issues (habitat function, ontogenetic 


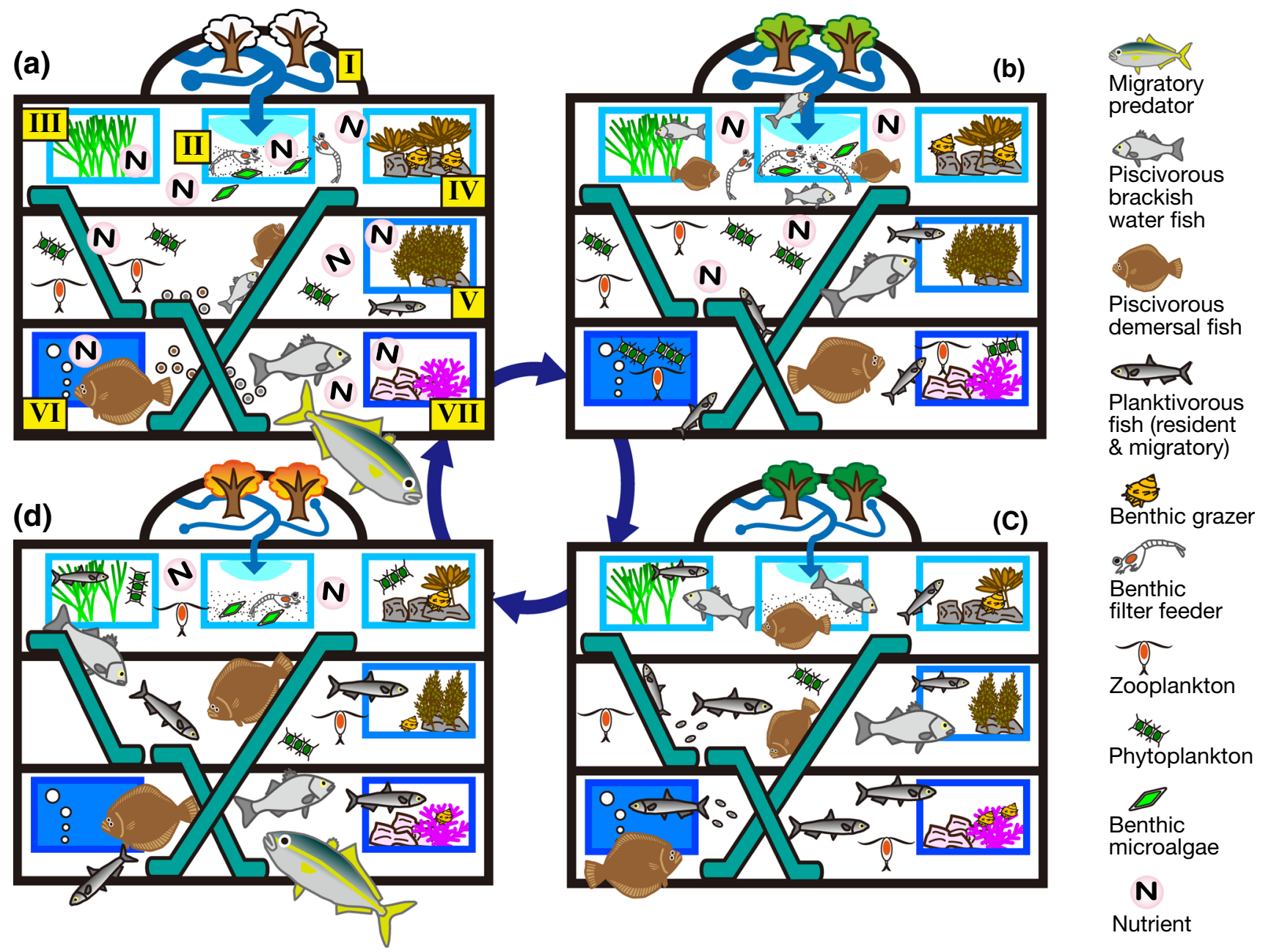

Fig. 3 Graphical model of a CEC for Tango Bay (Japan), schematically represented as a network for a winter, $\mathbf{b}$ spring, $\mathbf{c}$ summer and $\mathbf{d}$ autumn. The network consists of four levels including seven habitats: river $(I)$, estuary with muddy/sandy bottom $(I I)$, seagrass bed (III), shallow seaweed meadow $(I V)$, deep seaweed meadow $(V)$, the water column (that is not closely linked to benthic habitats) (VI), and coralline algae at the offshore margin (VII). The four levels, including

development from planktonic larvae to benthic/nektonic juvenile, and recruitment variability) that have been identified in case studies of the special issue as being important (Fuji et al. 2018; Hasegawa et al. 2018; Hayakawa et al. 2018; Ichimi et al., unpublished data; Kasai et al. 2018; Minami et al. 2018; Ohtsuchi et al. 2018; Shirafuji et al. 2018; Takami and Kawamura 2018; Tanaka et al. 2018; Sawada et al. unpublished data).

Habitat-organism associations occur because each habitat has an important function for each organism. An important role of structural habitats (e.g. , seagrass beds and seaweed meadows) for some organisms is that they act as refuges from predation. Ecospace can consider this aspect through the foraging arena algorithm (Walters et al. 1999); the refuge effects of habitats can also be set to depend on the biomass that of river, roughly correspond to water depths. Escalators represent pathways between habitats in different depth zones. The different sizes of each pictographic functional group (piscivorous and planktivorous fishes, and benthic grazers) indicate either adult (large) or juvenile (small) stages, while eggs are shown as circles or ellipses behind the adults

of habitat-forming organisms (e.g., biomass of seagrass) through an additional term called "mediation function," but it was recommended to handle this function with care as the results are often very sensitive to the form of the function (Harvey and Rose 2014). Atlantis expresses this slightly more mechanistically by formulating the refuge coefficient from the coverage of suitable habitat (Fulton et al. 2004a). However, in this regard, there have been profound revelations during field surveys. Seagrass beds may be safe for small fish during the day, but the presence of nocturnal predators makes the trophic interactions associated with seagrass beds more complex (Tanaka et al. 2018). In addition to refuge functions, physically irregular benthic or structural biotic habitats attenuate tidal flows and disturbances, and for some organisms increase the surface area available 
as substrates for spawning and settlement. The inclusion of more direct representation of structural habitats, rather than parameterizing roles such as refuge function, is expected in future modeling of the CEC.

Development from planktonic larvae to benthic/nektonic juvenile stages and recruitment variability are related issues. Many coastal animals have planktonic larval stages that proceed to benthic or nektonic juvenile stages. For these animals, mortality during the early life stages from predation, starvation, or other causes is generally high compared with mortality during adult stages, and this often results in large variability in annual recruitment. IBMs coupled with hydrodynamic/biogeochemical models including NEMURO. FISH/SAN (Megrey et al. 2007; Rose et al. 2015) and OSMOSE (Halouani et al. 2016; Travers-Trolet et al. 2014) have advantages in resolving life histories. Indeed, Rose et al. (2015) modeled the entire life cycles of sardine and anchovy in the California Current System. If these models included benthic habitats they would be able to model settlement from planktonic stages to the benthos, and the subsequent ontogenetic habitat shifts (Hayakawa et al. 2018; Minami et al. 2018; Ohtsuchi et al. 2018; Takami and Kawamura 2018; Sawada et al., unpublished data). Although Ecospace and Atlantis include benthic habitats and generally consider finer trophic networks than do IBMs, the resolution of early life history stages is relatively coarse, partly because of the high computational cost. The default time step of the current version of Ecospace is 1 month (Christensen et al. 2005), and the current version of Atlantis does not include planktonic larval stages (Fulton et al. 2004a, 2007). To incorporate greater temporal or stage resolution for early life stages in these models, some simplification in other parts of the models may be needed to reduce the computational cost.

In addition to anthropogenic stresses, natural recruitment variability is a major factor influencing biomass fluctuations among marine resources, and has been a main focus of fisheries research. Because ecosystem models formulate ecological processes derived from field observations, they cannot mechanistically reproduce the recruitment variability in the absence of understanding of the underlying processes. Nevertheless, based on hypotheses, it is possible for models to include early life history mortality processes that directly influence recruitment variability; however, these would need to be validated by future observations. Integrated models such as Ecospace and Atlantis are not designed to investigate recruitment processes, as they do not have the fine resolution required for early life stages (Christensen et al. 2005; Fulton et al. 2004a, 2007). Atlantis can reflect the importance of the juvenile habitat through inclusion of a recruitment coefficient for each habitat, but this does not resolve recruitment processes. Focusing on early life history stages and incorporation of the results of field surveys are needed to address this issue.
Finally, because the aim of the CEC concept was the sustainable use of coastal living marine resources (Watanabe et al. 2018), management perspectives are also important. The importance of ecosystem-based management has been widely recognized, in which ecosystem models are expected to play major roles (Grüss et al. 2017; Kaplan and Marshall 2016; Lehuta et al. 2016). Although we have discussed model development that includes detailed ecological processes suggested from observations, one problem is that this will also increase parameter uncertainty (Collie et al. 2016). Models of intermediate complexity may thus be feasible for management use (Plagányi et al. 2014).

\section{Summary}

To aid future numerical modeling of CEC, in this study we reviewed and discussed the modeling stages, the CEC and related concepts, and existing coastal ecosystem model frameworks. We identified two paths from objectives for numerical models: specific model building and use of existing models. As the CEC is still at the conceptual stage, both paths should be pursued. We also identified four important ecological features for CEC modeling: population connectivity, habitat heterogeneity, ontogeny of organisms, and trophic interactions. Population connectivity, species distributions, life histories, and food web models were categorized using these features. Of note, the BHI (Hori 2008), CEM (Sheaves 2009), and SSN (Nagelkerken et al. 2015) concepts have some overlap with the CEC concept. We reviewed existing model frameworks including NEMURO.FISH/SAN, OSMOSE, Ecospace, and Atlantis with respect to their potential to model CEC processes. Three issues which need to be considered in future CEC models were identified: habitat function, ontogenetic development from planktonic larvae to benthic/nektonic juveniles, and recruitment variability. These have been identified as being important in case studies presented in this special issue. While model complexity is increased when considering observed ecological processes, the complexity of models for fisheries management should be intermediate to moderately decrease parameter uncertainty.

Acknowledgements This research was supported by the Coastal Ecosystem Complex Project of the Ocean Resource Use Promotion Technology Development Program, funded by the Ministry of Education, Culture, Sports, Science and Technology of Japan, and by MEXT/ JSPS KAKENHI Grants JP26929099 and JP24121002. The authors thank Isaac Kaplan for his helpful comments on an early draft of the manuscript. 
Open Access This article is distributed under the terms of the Creative Commons Attribution 4.0 International License (http://creativeco mmons.org/licenses/by/4.0/), which permits unrestricted use, distribution, and reproduction in any medium, provided you give appropriate credit to the original author(s) and the source, provide a link to the Creative Commons license, and indicate if changes were made.

\section{References}

Adkins ME, Simpfendorfer CA, Tobin AJ (2016) Large tropical fishes and their use of the nearshore littoral, intertidal and subtidal habitat mosaic. Mar Freshw Res 67:1534-1545. https://doi. org/10.1071/mf14339

Ainsworth CH, Schirripa MJ, Morzaria-Luna HN (eds) (2015) An Atlantis ecosystem model for the Gulf of Mexico supporting integrated ecosystem assessment. Techcnical report, Tech Mem NMFS-SEFSC-676. NOAA, Miami, FL. https://doi.org/10.7289/ V5X63JVH

Allen JI, Blackford J, Holt J, Proctor R, Ashworth M, Siddorn J (2012) A highly spatially resolved ecosystem model for the North West European Continental Shelf. Sarsia 86:423-440. https://doi. org/10.1080/00364827.2001.10420484

Aumont O, Bopp L (2006) Globalizing results from ocean in situ iron fertilization studies. Glob Biogeochem Cycle. https://doi. org/10.1029/2005gb002591

Barbour AB, Adams AJ, Lorenzen K (2014) Size-based, seasonal, and multidirectional movements of an estuarine fish species in a habitat mosaic. Mar Ecol Prog Ser 507:263-276. https://doi. org/10.3354/meps10837

Baretta JW, Ebenhöh W, Ruardij P (1995) The European regional seas ecosystem model, a complex marine ecosystem model. Neth J Sea Res 33:233-246. https://doi.org/10.1016/00777579(95)90047-0

Baretta-Bekker JG, Baretta JW, Ebenhoh W (1997) Microbial dynamics in the marine ecosystem model ERSEM II with decoupled carbon assimilation and nutrient uptake. J Sea Res 38:195-211. https://doi.org/10.1016/s1385-1101(97)00052-x

Bostrom C, Pittman SJ, Simenstad C, Kneib RT (2011) Seascape ecology of coastal biogenic habitats: advances, gaps, and challenges. Mar Ecol Prog Ser 427:191-217. https://doi.org/10.3354/meps0 9051

Butenschön M, Clark J, Aldridge JN, Allen JI, Artioli Y, Blackford J, Bruggeman J, Cazenave P, Ciavatta S, Kay S, Lessin G, van Leeuwen S, van der Molen J, de Mora L, Polimene L, Sailley S, Stephens N, Torres R (2016) ERSEM15.06: a generic model for marine biogeochemistry and the ecosystem dynamics of the lower trophic levels. Geosci Model Dev 9:1293-1339. https:// doi.org/10.5194/gmd-9-1293-2016

Cai WJ (2011) Estuarine and coastal ocean carbon paradox: $\mathrm{CO}_{2}$ sinks or sites of terrestrial carbon incineration? Annu Rev Mar Sci 3:123-145

Cheung WWL, Lam VWY, Pauly D (2008) Dynamic bioclimate envelope model to predict climate-induced changes in distribution of marine fishes and invertebrates. University of British Columnbia, Vancouver

Cheung WWL, Brodeur RD, Okey TA, Pauly D (2015) Projecting future changes in distributions of pelagic fish species of Northeast Pacific Shelf seas. Prog Oceanogr 130:19-31. https://doi. org/10.1016/j.pocean.2014.09.003

Christensen V, Walters CJ (2004) Ecopath with Ecosim: methods, capabilities and limitations. Ecol Model 172:109-139. https:// doi.org/10.1016/j.ecolmodel.2003.09.003
Christensen V, Walters CJ, Pauly D (2005) Ecopath with Ecosim: a user's guide. Fisheries Centre, University of British Columbia, Vancouver

Christensen V, Coll M, Steenbeek J, Buszowski J, Chagaris D, Walters CJ (2014) Representing variable habitat quality in a spatial food web model. Ecosystems 17:1397-1412. https://doi.org/10.1007/ s10021-014-9803-3

Coll M, Palomera I, Tudela S, Sardà F (2006) Trophic flows, ecosystem structure and fishing impacts in the South Catalan Sea, Northwestern Mediterranean. J Mar Syst 59:63-96. https://doi. org/10.1016/j.jmarsys.2005.09.001

Coll M, Steenbeek J, Sole J, Palomera I, Christensen V (2016) Modelling the cumulative spatial-temporal effects of environmental drivers and fishing in a NW Mediterranean marine ecosystem. Ecol Model 331:100-114. https://doi.org/10.1016/j.ecolm odel.2016.03.020

Collie JS, Botsford LW, Hastings A, Kaplan IC, Largier JL, Livingston PA, Plaganyi E, Rose KA, Wells BK, Werner FE (2016) Ecosystem models for fisheries management: finding the sweet spot. Fish Fish 17:101-125. https://doi.org/10.1111/faf.12093

Cowen RK (2000) Connectivity of marine populations: open or closed? Science 287:857-859. https://doi.org/10.1126/scien ce. 287.5454 .857

Cowen RK (2002) Larval dispersal, retention and consequences for population connectivity. In: Sale PF (ed) Ecology of coral reef fishes: recent advances. Academic Press, San Diego, pp 149-170

Cowen RK, Sponaugle S (2009) Larval dispersal, marine population connectivity. Annu Rev Mar Sci 1:443-466. https://doi. org/10.1146/annurev.marine.010908.163757

Cranford PJ, Strain PM, Dowd M, Hargrave BT, Grant J, Archambault MC (2007) Influence of mussel aquaculture on nitrogen dynamics in a nutrient enriched coastal embayment. Mar Ecol Prog Ser 347:61-78. https://doi.org/10.3354/meps06997

Criales MM, Cherubin LM, Browder JA (2015) Modeling larval transport and settlement of pink shrimp in South Florida: dynamics of behavior and tides. Mar Coast Fish 7:148-176. https://doi. org/10.1080/19425120.2014.1001541

Cuadros A, Joan MB, Luis CC, Thiriet P, Pastor J, Arroyo NL, Cheminee A (2017) Seascape attributes, at different spatial scales, determine settlement and post-settlement of juvenile fish. Estuar Coast Shelf S 185:120-129. https://doi.org/10.1016/j. ecss.2016.12.014

Davis JP, Pitt KA, Fry B, Olds AD, Connolly RM (2014) Seascapescale trophic links for fish on inshore coral reefs. Coral Reefs 33:897-907. https://doi.org/10.1007/s00338-014-1196-4

de Graaf M, Jager Z, Vreugdenhil CB, Elorche M (2004) Numerical simulations of tidally cued vertical migrations of flatfish larvae in the North Sea. Estuar Coast Shelf S 59:295-305. https://doi. org/10.1016/j.ecss.2003.09.010

Doney SC, Lima I, Moore JK, Lindsay K, Behrenfeld MJ, Westberry TK, Mahowald N, Glover DM, Takahashi T (2009) Skill metrics for confronting global upper ocean ecosystem-biogeochemistry models against field and remote sensing data. J Mar Syst 76:95112. https://doi.org/10.1016/j.jmarsys.2008.05.015

Duarte CM (2017) Reviews and syntheses: hidden forests, the role of vegetated coastal habitats in the ocean carbon budget. Biogeosciences 14:301-310. https://doi.org/10.5194/bg-14-301-2017

Elith J, Leathwick JR (2009) Species distribution models: ecological explanation and prediction across space and time. Annu Rev Ecol Evol Syst 40:677-697. https://doi.org/10.1146/annurev.ecols ys.110308.120159

Essington TE, Plaganyi EE (2013) Pitfalls and guidelines for "recycling" models for ecosystem-based fisheries management: evaluating model suitability for forage fish fisheries. ICES J Mar Sci 71:118-127. https://doi.org/10.1093/icesjms/fst047 
Fasham MJR, Ducklow HW, Mckelvie SM (1990) A nitrogen-based model of plankton dynamics in the oceanic mixed layer. J Mar Res 48:591-639

Fennel W (2008) Towards bridging biogeochemical and fish-production models. J Mar Syst 71:171-194. https://doi.org/10.1016/j. jmarsys.2007.06.008

Fennel W, Neumann T (2004) Introduction to the modelling of marine ecosystems. Elsevier Science, Amsterdam

Fiechter J, Huckstadt LA, Rose KA, Costa DP (2016) A fully coupled ecosystem model to predict the foraging ecology of apex predators in the California Current. Mar Ecol Prog Ser 556:273-285. https://doi.org/10.3354/meps11849

Fuji T, Kasai A, Ueno M, Yamashita Y (2014) Growth and migration patterns of juvenile temperate seabass Lateolabrax japonicus in the Yura River Estuary, Japan-combination of stable isotope ratio and otolith microstructure analyses. Environ Biol Fish 97:12211232. https://doi.org/10.1007/s10641-013-0209-4

Fuji T, Kasai A, Yamashita Y (2018) Upstream migration mechanisms of juvenile temperate seabass Lateolabrax japonicus in the stratified Yura River Estuary. Fish Sci. https://doi.org/10.1007/s1256 2-017-1167-0

Fulton EA (2010) Approaches to end-to-end ecosystem models. J Mar Syst 81:171-183. https://doi.org/10.1016/j.jmarsys.2009.12.012

Fulton EA, Fuller M, Smith ADM, Punt AE (2004a) Ecological indicators of the ecosystem effects of fishing: final report. Techcnical report, R99/1546, CSIRO, Canberra

Fulton EA, Parslow JS, Smith ADM, Johnson CR (2004b) Biogeochemical marine ecosystem models. II. The effect of physiological detail on model performance. Ecol Model 173:371-406

Fulton EA, Smith ADM, Smith DC (2007) Alternative management strategies for Southeast Australian Commonwealth fisheries. Stage 2. Quantitative management strategy evaluation. CSIRO, Canberra

Fulton EA, Link JS, Kaplan IC, Savina-Rolland M, Johnson P, Ainsworth C, Horne P, Gorton R, Gamble RJ, Smith ADM, Smith DC (2011) Lessons in modelling and management of marine ecosystems: the Atlantis experience. Fish Fish 12:171-188. https ://doi.org/10.1111/j.1467-2979.2011.00412.x

Fulton EA, Smith ADM, Smith DC, Johnson P (2014) An integrated approach is needed for ecosystem based fisheries management: insights from ecosystem-level management strategy evaluation. PLoS One. https://doi.org/10.1371/journal.pone.0084242

Gaichas S, Skaret G, Falk-Petersen J, Link JS, Overholtz W, Megrey BA, Gjøsæter H, Stockhausen WT, Dommasnes A, Friedland KD, Aydin K (2009) A comparison of community and trophic structure in five marine ecosystems based on energy budgets and system metrics. Prog Oceanogr 81:47-62. https://doi. org/10.1016/j.pocean.2009.04.005

Girardin R, Fulton EA, Lehuta S, Rolland M, Thébaud O, TraversTrolet M, Vermard Y, Marchal P (2016) Identification of the main processes underlying ecosystem functioning in the Eastern English Channel, with a focus on flatfish species, as revealed through the application of the Atlantis end-to-end model. Estuar Coast Shelf Sci. https://doi.org/10.1016/j.ecss.2016.10.016

Grüss A, Schirripa MJ, Chagaris D, Drexler M, Simons J, Verley P, Shin YJ, Karnauskas M, Oliveros-Ramos R, Ainsworth CH (2015) Evaluation of the trophic structure of the West Florida Shelf in the 2000s using the ecosystem model OSMOSE. J Mar Syst 144:30-47. https://doi.org/10.1016/j.jmarsys.2014.11.004

Grüss A, Rose KA, Simons J, Ainsworth CH, Babcock EA, Chagaris DD, De Mutsert K, Froeschke J, Himchak P, Kaplan IC, O'Farrell H, Zetina Rejon MJ (2017) Recommendations on the use of ecosystem modeling for informing ecosystem-based fisheries management and restoration outcomes in the Gulf of Mexico. Mar Coast Fish 9:281-295. https://doi.org/10.1080/19425 120.2017.1330786
Haidvogel DB, Arango H, Budgell WP, Cornuelle BD, Curchitser E, Di Lorenzo E, Fennel K, Geyer WR, Hermann AJ, Lanerolle L, Levin J, McWilliams JC, Miller AJ, Moore AM, Powell TM, Shchepetkin AF, Sherwood CR, Signell RP, Warner JC, Wilkin J (2008) Ocean forecasting in terrain-following coordinates: formulation and skill assessment of the Regional Ocean Modeling System. J Comput Phys 227:3595-3624. https://doi. org/10.1016/j.jcp.2007.06.016

Halouani G, Lasram FB, Shin YJ, Velez L, Verley P, Hattab T, Oliveros-Ramos R, Diaz F, Menard F, Baklouti M, Guyennon A, Romdhane MS, Le Loc'h F (2016) Modelling food web structure using an end-to-end approach in the coastal ecosystem of the Gulf of Gabes (Tunisia). Ecol Model 339:45-57. https:// doi.org/10.1016/j.ecolmodel.2016.08.008

Harvey CJ, Rose K (2014) Mediation functions in Ecopath with Ecosim: handle with care. Can J Fish Aquat Sci 71:1020-1029. https://doi.org/10.1139/cjfas-2013-0594

Harvey CJ, Reum JCP, Poe MR, Williams GD, Kim SJ (2016) Using conceptual models and qualitative network models to advance integrative assessments of marine ecosystems. Coast Manage 44:486-503. https://doi.org/10.1080/08920753.2016.1208881

Hasegawa N, Abe H, Onitsuka T, Ito S (2018) Association between the planktonic larval and benthic stages of Manila clam Ruditapes philippinarum in eastern Hokkaido, Japan. Fish Sci. https ://doi.org/10.1007/s12562-017-1168-z

Hata K, Nakata K, Suzuki T (2004) The nitrogen cycle in tidal flats and eelgrass beds of Ise Bay. J Mar Syst 45:237-253. https:// doi.org/10.1016/j.jmarsys.2003.11.007

Hattab T, Albouy C, Lasram FBR, Somot S, Le Loc'h F, Leprieur F (2014) Towards a better understanding of potential impacts of climate change on marine species distribution: a multiscale modelling approach. Glob Ecol Biogeogr 23:1417-1429. https ://doi.org/10.1111/geb.12217

Hayakawa J, Ohtsuchi N, Kawamura T, Kurogi H, Watanabe Y (2018) Ontogenetic changes in habitat use and feeding habit of the turban snail Turbo cornutus. Fish Sci. https://doi. org/10.1007/s12562-017-1170-5

Hilborn R, Walters CJ (1992) Quantitative fisheries stock assessment, choice, dynamics and uncertainty. Kluwer, Dordrecht

Hori M (2008) Between-habitat interactions in coastal ecosystems: current knowledge and future challenges for understanding community dynamics. Plank Benth Res 3:53-63. https://doi. org/10.3800/pbr.3.53

Ihde TF, Townsend HM (2017) Accounting for multiple stressors influencing living marine resources in a complex estuarine ecosystem using an Atlantis model. Ecol Model 365:1-9. https:// doi.org/10.1016/j.ecolmodel.2017.09.010

Ihde TF, Kaplan IC, Fulton EA, Gray IA, Hasan M, Bruce D, Slacum W, Townsend HM (2016) Design and parameterization of the Chesapeake Bay Atlantis model: a spatially explicit end-to-end ecosystem model. Technical report, NOAA Tech Mem NMFSF/SPO-166, Annapolis, MD

Ito S-I, Kishi MJ, Kurita Y, Oozeki Y, Yamanaka Y, Megrey BA, Werner FE (2004) Initial design for a fish bioenergetics model of Pacific saury coupled to a lower trophic ecosystem model. Fish Oceanogr 13:111-124. https://doi.org/10.111 $1 / \mathrm{j} .1365-2419.2004 .00307 . x$

James ID (2002) Modelling pollution dispersion, the ecosystem and water quality in coastal waters: a review. Environ Model Softw 17:363-385. https://doi.org/10.1016/s1364-8152(01)00080-9

Jones GP, Almany GR, Russ GR, Sale PF, Steneck RS, van Oppen MJH, Willis BL (2009) Larval retention and connectivity among populations of corals and reef fishes: history, advances and challenges. Coral Reefs 28:307-325. https://doi. org/10.1007/s00338-009-0469-9 
Jones MC, Dye SR, Pinnegar JK, Warren R, Cheung WWL (2012) Modelling commercial fish distributions: prediction and assessment using different approaches. Ecol Model 225:133145. https://doi.org/10.1016/j.ecolmodel.2011.11.003

Kaplan IC, Marshall KN (2016) A guinea pig's tale: learning to review end-to-end marine ecosystem models for management applications. ICES J Mar Sci 73:1715-1724. https://doi. org/10.1093/icesjms/fsw047

Kaplan IC, Koehn LE, Hodgson EE, Marshall KN, Essington TE (2017) Modeling food web effects of low sardine and anchovy abundance in the California Current. Ecol Model 359:1-24. https://doi.org/10.1016/j.ecolmodel.2017.05.007

Kasai A, Fuji T, Suzuki KW, Yamashita Y (2018) Partial migration of juvenile temperate seabass Lateolabrax japonicus-a versatile survival strategy. Fish Sci. https://doi.org/10.1007/ s12562-017-1166-1

Kimura S, Kishi MJ, Nakata H, Yamashita Y (1992) A numerical analysis of population dynamics of the sand lance (Ammodytes personatus) in the eastern Seto Inland Sea, Japan. Fish Oceanogr 1:321-332. https://doi.org/10.1111/j.1365-2419.1992. tb00004.x

Kishi MJ, Uchiyama M (1995) A three-dimensional numerical model for a mariculture nitrogen cycle: case study in Shizugawa Bay, Japan. Fish Oceanogr 4:303-316. https://doi. org/10.1111/j.1365-2419.1995.tb00075.x

Kishi MJ, Nakata K, Ishikawa K (1981) Sensitivity analysis of a coastal marine ecosystem. J Oceanogr Soc Jpn 37:120-134. https://doi.org/10.1007/bf02308096

Kishi MJ, Kimura S, Nakata H, Yamashita Y (1991) A biomassbased model for the sand lance (Ammodytes personatus) in Seto Inland Sea, Japan. Ecol Model 54:247-263. https://doi. org/10.1016/0304-3800(91)90078-f

Kishi MJ, Kashiwai M, Ware DM, Megrey BA, Eslinger DL, Werner FE, Noguchi-Aita M, Azumaya T, Fujii M, Hashimoto S, Huang DJ, Iizumi H, Ishida Y, Kang S, Kantakov GA, Kim HC, Komatsu K, Navrotsky VV, Smith SL, Tadokoro K, Tsuda A, Yamamura O, Yamanaka Y, Yokouchi K, Yoshie N, Zhang J, Zuenko YI, Zvalinsky VI (2007) NEMURO—a lower trophic level model for the North Pacific marine ecosystem. Ecol Model 202:12-25

Kishi MJ, Ito S, Megrey BA, Rose KA, Werner FE (2011) A review of the NEMURO and NEMURO.FISH models and their application to marine ecosystem investigations. J Oceanogr 67:316. https://doi.org/10.1007/s10872-011-0009-4

Kiyota M, Yonezaki S, Watari S (2016) A practical guide to ecosystem modeling based on Ecopath with Ecosim software and fishery-related data. Bull Jpn Soc Fish Oceanogr 80:34-47 (in Japanese with English abstract)

Kremer J, Nixon SW (1978) A coastal marine ecosystem, siimulation and analysis. Springer, Heidelberg Berlin New York

Kritzer J, Sale P (2006) PREFACE. In: Kritzer J, Sale P (eds) Marine metapopulations. Academic Press, Burlington, pp xxi-xxiii

Kurita Y, Okazaki Y, Yamashita Y (2018) Ontogenetic habitat shift of age-0 Japanese flounder Paralichthys olivaceus on the Pacific coast of northeastern Japan: differences in timing of the shift among areas and potential effects on recruitment successs. Fish Sci. https://doi.org/10.1007/s12562-01x-Xxxxxx

Lacroix G, Ruddick K, Park Y, Gypens N, Lancelot C (2007) Validation of the 3D biogeochemical model MIRO\&CO with field nutrient and phytoplankton data and MERIS-derived surface chlorophyll a images. J Mar Syst 64:66-88. https://doi. org/10.1016/j.jmarsys.2006.01.010

Le Quere C, Harrison SP, Prentice IC, Buitenhuis ET, Aumont O, Bopp L, Claustre H, Da Cunha LC, Geider R, Giraud X, Klaas C, Kohfeld KE, Legendre L, Manizza M, Platt T, Rivkin RB, Sathyendranath S, Uitz J, Watson AJ, Wolf-Gladrow D (2005)
Ecosystem dynamics based on plankton functional types for global ocean biogeochemistry models. Globa Chang Biol 11:2016-2040

Lehuta S, Girardin R, Mahévas S, Travers-Trolet M, Vermard Y (2016) Reconciling complex system models and fisheries advice: practical examples and leads. Aquat Living Resour 29:208. https://doi. org/10.1051/alr/2016022

Lipcius RN, Eggleston DB, Schreiber SJ, Seitz RD, Shen J, Sisson M, Stockhausen WT, Wang HV (2008) Importance of metapopulation connectivity to restocking and restoration of marine species. Rev Fish Sci 16:101-110. https://doi.org/10.1080/1064126070 1812574

Loreau M, Mouquet N, Holt RD (2003) Meta-ecosystems: a theoretical framework for a spatial ecosystem ecology. Ecol Lett 6:673-679. https://doi.org/10.1046/j.1461-0248.2003.00483.x

Mangnússon KG (1995) An overview of the multispecies VPAtheory and applications. Rev Fish Biol Fisher 5:195-212

Mann KH (2000) Ecology of coastal waters: with implications for management. Wiley, Malden

Marine Steward Council (2014) MSC fisheries standard and guidance v2.0. London, pp 290

Megrey BA, Rose KA, Klumb RA, Hay DE, Werner FE, Eslinger DL, Smith SL (2007) A bioenergetlics-based population dynamics model of Pacific herring (Clupea harengus pallasi) coupled to a lower trophic level nutrient-phytoplanktonzooplankton model: description, calibration, and sensitivity analysis. Ecol Model 202:144-164. https://doi.org/10.1016/j. ecolmodel.2006.08.020

Melbourne-Thomas J, Wotherspoon S, Raymond B, Constable A (2012) Comprehensive evaluation of model uncertainty in qualitative network analyses. Ecol Monogr 82:505-519. https://doi. org/10.1890/12-0207.1

Menge BA, Gouhier TC, Hacker SD, Chan F, Nielsen KJ (2015) Are meta-ecosystems organized hierarchically? A model and test in rocky intertidal habitats. Ecol Monogr 85:213-233. https://doi. org/10.1890/14-0113.1

Minami K, Sawada H, Masuda R, Takahashi K, Shirakawa H, Yamashita Y (2018) Stage specific distribution of Japanese sea cucumber Apostichopus japonicus in Maizuru Bay, Sea of Japan in relation to environmental factors. Fish Sci. https://doi.org/10.1007/s1256 2-017-1174-1

Mitarai S, Siegel DA, Winters KB (2008) A numerical study of stochastic larval settlement in the California Current system. J Mar Syst 69:295-309. https://doi.org/10.1016/j.jmarsys.2006.02.017

Mitarai S, Siegel DA, Watson JR, Dong C, McWilliams JC (2009) Quantifying connectivity in the coastal ocean with application to the Southern California Bight. J Geophys Res. https://doi. org/10.1029/2008jc005166

Miyake Y, Kimura S, Kawamura T, Kitagawa T, Takahashi T, Takami H (2011) Population connectivity of Ezo abalone on the northern Pacific coast of Japan in relation to the establishment of harvest refugia. Mar Ecol Prog Ser 440:137-150. https://doi. org/10.3354/meps09348

Moll A, Radach G (2003) Review of three-dimensional ecological modelling related to the North Sea shelf system. Part 1. Models and their results. Prog Oceanogr 57:175-217. https://doi. org/10.1016/s0079-6611(03)00067-3

Moore JK, Doney SC, Lindsay K (2004) Upper ocean ecosystem dynamics and iron cycling in a global three-dimensional model. Global Biogeochem C. https://doi.org/10.1029/2004gb002220

Murase H, Nagashima H, Yonezaki S, Matsukura R, Kitakado T (2009) Application of a generalized additive model (GAM) to reveal relationships between environmental factors and distributions of pelagic fish and krill: a case study in Sendai Bay, Japan. ICES J Mar Sci 66:1417-1424. https://doi.org/10.1093/icesjms/fsp105 
Nagelkerken I, Sheaves M, Baker R, Connolly RM (2015) The seascape nursery: a novel spatial approach to identify and manage nurseries for coastal marine fauna. Fish Fish 16:362-371. https://doi. org/10.1111/faf.12057

Nishihira M (2006) Ecology of footing. Heibon-sha, Tokyo

Nobre AM, Ferreira JG, Nunes JP, Yan XJ, Bricker S, Corner R, Groom S, Gu HF, Hawkins AJS, Hutson R, Lan DZ, Lencart e Silva JD, Pascoe P, Telfer T, Zhang XL, Zhu MY (2010) Assessment of coastal management options by means of multilayered ecosystem models. Estuar Coast Shelf Sci 87:43-62. https://doi. org/10.1016/j.ecss.2009.12.013

Odum EP, Barrett GW (2004) Fundamentals of ecology. Brooks/ Cole, Belmont

Ohtsuchi N, Kawamura T, Hayakawa J, Kurogi H, Watanabe Y (2018) Ontogenetic habitat shift in Pugettia quadridens on the coast of Sagami Bay, Japan. Fish Sci. https://doi.org/10.1007/ s12562-017-1171-4

Okubo A, Levin SA (2001) Diffusion and ecological problemsmodern perspectives. Springer, New York

Olds AD, Connolly RM, Pitt KA, Maxwell PS (2012) Primacy of seascape connectivity effects in structuring coral reef fish assemblages. Mar Ecol Prog Ser 462:191-203. https://doi. org/10.3354/meps09849

Onaka S, Prasetyo R, Endo S, Yoshii I (2013) Large-scale coral transplantation in artificial substrates at a shallow lagoon in Kuta Beach, Bali, Indonesia. Galaxea 15:336-342. https://doi. org/10.3755/galaxea.15.336

Pacific Fisheries Management Council, and National Marine Fisheries Service (2015) Final EIS for Pacific coast groundfish harvest specifications and management measures for 2015-2016 and biennial periods thereafter, and amendment 24 to the Pacific Coast Groundfish Fishery Management Plan. Technical report. Portland OR, Seattle, WA

Paris CB, Helgers J, van Sebille E, Srinivasan A (2013) Connectivity modeling system: a probabilistic modeling tool for the multiscale tracking of biotic and abiotic variability in the ocean. Environ Model Softw 42:47-54. https://doi.org/10.1016/j. envsoft.2012.12.006

Pauly D, Christensen V, Walters C (2000) Ecopath, Ecosim, and Ecospace as tools for evaluating ecosystem impact of fisheries. ICES J Mar Sci 57:697-706. https://doi.org/10.1006/ jmsc. 2000.0726

Pittman SJ, Brown KA (2011) Multi-scale approach for predicting fish species distributions across coral reef seascapes. PLoS One. https://doi.org/10.1371/journal.pone.0020583

Plagányi ÉE, Punt AE, Hillary R, Morello EB, Thébaud O, Hutton T, Pillans RD, Thorson JT, Fulton EA, Smith ADM, Smith F, Bayliss P, Haywood M, Lyne V, Rothlisberg PC (2014) Multispecies fisheries management and conservation: tactical applications using models of intermediate complexity. Fish Fish 15:1-22. https://doi.org/10.1111/j.1467-2979.2012.00488.x

Quinn TJ, Deriso RB (1999) Quantitative fish dynamics. Oxford University Press, Oxford

Radtke H, Neumann T, Fennel W (2013) A Eulerian nutrient to fish model of the Baltic Sea-a feasibility-study. J Mar Syst 125:61-76. https://doi.org/10.1016/j.jmarsys.2012.07.010

Reiss H, Cunze S, Konig K, Neumann H, Kroncke I (2011) Species distribution modelling of marine benthos: a North Sea case study. Mar Ecol Prog Ser 442:71-86. https://doi.org/10.3354/ meps09391

Rose KA, Fiechter J, Curchitser EN, Hedstrom K, Bernal M, Creekmore S, Haynie A, Ito S, Lluch-Cota S, Megrey BA, Edwards CA, Checkley D, Koslow T, McClatchie S, Werner F, MacCall A, Agostini V (2015) Demonstration of a fully-coupled endto-end model for small pelagic fish using sardine and anchovy in the California Current. Prog Oceanogr 138:348-380. https ://doi.org/10.1016/j.pocean.2015.01.012

Savina M, Lunghi M, Archambault B, Baulier L, Huret M, Le Pape O (2016) Sole larval supply to coastal nurseries: interannual variability and connectivity at interregional and interpopulation scales. J Sea Res 111:1-10. https://doi.org/10.1016/j.seare s.2015.11.010

Shchepetkin AF, McWilliams JC (2005) The regional oceanic modeling system (ROMS): a split-explicit, free-surface, topographyfollowing-coordinate oceanic model. Ocean Model 9:347-404. https://doi.org/10.1016/j.ocemod.2004.08.002

Sheaves M (2009) Consequences of ecological connectivity: the coastal ecosystem mosaic. Mar Ecol Prog Ser 391:107-115. https://doi. org/10.3354/meps08121

Shigemitsu M, Okunishi T, Nishioka J, Sumata H, Hashioka T, Aita MN, Smith SL, Yoshie N, Okada N, Yamanaka Y (2012) Development of a one-dimensional ecosystem model including the iron cycle applied to the Oyashio region, western subarctic Pacific. J Geophys Res. https://doi.org/10.1029/2011jc007689

Shin Y, Cury P (2001) Exploring fish community dynamics through size-dependent trophic interactions using a spatialized individual-based model. Aquat Living Resour 14:65-80. https://doi. org/10.1016/s0990-7440(01)01106-8

Shin YJ, Cury P (2004) Using an individual-based model of fish assemblages to study the response of size spectra to changes in fishing. Can J Fish Aquat Sci 61:414-431. https://doi.org/10.1139/ f03-154

Shirafuji N, Nakagawa T, Murakami N, Ito S, Onituka T, Morioka T, Watanabe Y (2018) Successive use of different habitats during the early life stages of Pacific herring Clupea pallasii in Akkeshi waters on the east coast of Hokkaido. Fish Sci. https://doi. org/10.1007/s12562-018-1175-8

Skilleter GA, Loneragan NR, Olds A, Zharikov Y, Cameron B (2017) Connectivity between seagrass and mangroves influences nekton assemblages using nearshore habitats. Mar Ecol Prog Ser 573:25-43. https://doi.org/10.3354/meps12159

Smith AD, Brown CJ, Bulman CM, Fulton EA, Johnson P, Kaplan IC, Lozano-Montes H, Mackinson S, Marzloff M, Shannon LJ, Shin YJ, Tam J (2011) Impacts of fishing low-trophic level species on marine ecosystems. Science 333:1147-1150. https://doi. org/10.1126/science.1209395

Sohma A, Sekiguchi Y, Yamada H, Sato T, Nakata K (2001) A new coastal marine ecosystem model study coupled with hydrodynamics and tidal flat ecosystem effect. Mar Pollut Bull 43:187208. https://doi.org/10.1016/s0025-326x(01)00083-2

Sohma A, Sekiguchi Y, Nakata K (2004) Modeling and evaluating the ecosystem of sea-grass beds, shallow waters without sea-grass, and an oxygen-depleted offshore area. J Mar Syst 45:105-142. https://doi.org/10.1016/j.jmarsys.2003.11.011

Sohma A, Sekiguchi Y, Kuwae T, Nakamura Y (2008) A benthicpelagic coupled ecosystem model to estimate the hypoxic estuary including tidal flat-model description and validation of seasonal/daily dynamics. Ecol Model 215:10-39. https://doi. org/10.1016/j.ecolmodel.2008.02.027

Takami H, Kawamura T (2018) Ontogenetic habitat shift in abalone Haliotis discus hannai: a review. Fish Sci. https://doi. org/10.1007/s12562-017-1169-y

Tanaka H, Chiba S, Yusa T, Shoji J (2018) Day-night change in fish community structure in a seagrass bed in subarctic waters. Fish Sci 84. https://doi.org/10.1007/s12562-017-1172-3

Travers-Trolet M, Shin YJ, Shannon LJ, Moloney CL, Field JG (2014) Combined fishing and climate forcing in the Southern Benguela upwelling ecosystem: an end-to-end modelling approach reveals dampened effects. PLoS One. https://doi.org/10.1371/journ al.pone.0094286 
Underwood GJC, Kromkamp J (1999) Primary production by phytoplankton and microphytobenthos in estuaries. 29:93-153. https ://doi.org/10.1016/s0065-2504(08)60192-0

Walters C, Pauly D, Christensen V (1999) Ecospace: prediction of mesoscale spatial patterns in trophic relationships of exploited ecosystems, with emphasis on the impacts of marine protected areas. Ecosystems 2:539-554. https://doi.org/10.1007/s100219900101

Watanabe Y, Kawamura T, Yamashita Y (2018) Introduction: the coastal ecosystem complex as a unit of structure and function of biological productivity in coastal areas. Fish Sci 84. https://doi. org/10.1007/s12562-018-1176-7

Weijerman M, Fulton EA, Kaplan IC, Gorton R, Leemans R, Mooij WM, Brainard RE (2015) An integrated coral reef ecosystem model to support resource management under a changing climate. PLoS One. https://doi.org/10.1371/journal.pone.0144165

Weijerman M, Fulton EA, Brainard RE (2016) Management strategy evaluation applied to coral reef ecosystems in support of ecosystem-based management. PLoS One. https://doi.org/10.1371/ journal.pone. 0152577
Werner F, Cowen R, Paris C (2007) Coupled biological and physical models: present capabilities and necessary developments for future studies of population connectivity. Oceanography 20:54 69. https://doi.org/10.5670/oceanog.2007.29

Wilson DS (1992) Complex interactions in metacommunities, with implications for biodiversity and higher levels of selection. Ecology 73:1984-2000. https://doi.org/10.2307/1941449

Xu J, Hood RR (2006) Modeling biogeochemical cycles in Chesapeake Bay with a coupled physical-biological model. Estuar Coast Shelf Sci 69:19-46. https://doi.org/10.1016/j.ecss.2006.03.021

Yonezaki S, Kiyota M, Narimatsu Y, Hattori T, Ito M (2016) Quantification of the demersal marine ecosystem structure in the northern district of the Tohoku sea area, northeastern Japan based on Ecopath approach. Bull Jpn Soc Fish Oceanogr 80:1-19 (in Japanese with English abstract)

Yoon S, Abe H, Kishi MJ (2013) Responses of Manila clam growth and its food sources to global warming in a subarctic lagoon in Japan. Prog Oceanogr 119:48-58. https://doi.org/10.1016/j. pocean.2013.06.005 